\title{
Support Centre for Visually Impaired Students
}

\author{
Ludmila Moravcikova \\ The Faculty of Mathematics and Physics, Comenius University, \\ Bratislava, SLOVAKIA
}

\begin{abstract}
The paper deals about problems, achievements and prospect of building the support Centre at the Comenius University in Bratislava. The support Centre of academic studies for the blind and partially sighted has been built within the project TEMPUS JEP 2423 "New Study and Vocational Possibilities for Visually Handicapped Students" at the Faculty of Mathematics and Physics since September 1992. The basic role of the Centre is to secure conditions for the integrated study of visually handicapped students at Comenius University and enable them to acquire education in the fields that have not been attainable before ...
\end{abstract}

\section{Introduction}

Our Centre has been built thanks to contacts with the Union of the Blind and Partially Sighted in Slovakia and with Mr. Mamojka, who have helped us to join the project TEMPUS. Slovakia was the part of Czechoslovakia, so the first idea was to build one Centre at the Technical University of Prague and the second one at our University. Centres in both cities have been cooperating since their establishment and also after the country was divided into two states.

The coordinator of the project is the University of Karlsruhe, where they have been realizing a pilot project, "Informatik für Blinde" since 1987. The main difference between the German and our Centre is in the scope of work. While the German Centre has focused its support mainly on future mathematicians, experts on informatics, and the students of industrial engineering, our Centre intends to promote studying in all fields according to their interest.

Since the Centre should work with modern computer equipment, special peripherials and software, the decision was made to place the Centre at the Faculty of Mathematics and Physics.

\section{The Main Achievements}

\subsection{The Technical Equipement}

The Centre is situated into two rooms, one of them is for sighted people who prepare study material for their handicapped colleagues and the second is for handicapped students. The technical equipement of the Centre is: 
- local Novell network with eleven computers and monitors of a different dimensions

- for blind students

- eighty cell Braille line

- two voice outputs

- for partially sighted students

- VGA reader

- colour reader

- programme LP DOS

- for sighted people transforming study material into appropriate form for handicapped people

- OCR system with scanner

- Braille printer

- dictaphones.

\subsection{The Staff of the Centre}

The staff of the Centre consists of five members:

- coordinating person

- technical person

- pedagogical and psychological councellor

- technical councellor

- the manager of tutoring system

Only pedagogical councellor has fulltime job in the Centre, other members of the staff are university teachers of informatics and they work in the Centre only partially. Non of us has had previous experiences with handicapped people. At the beginning we went through study visits in Germany, Great Britain, Canada and USA, where we learnt how to use special devices for the blind, how to handle blind people and which kind of services are necessary for the successful study of visually handicapped students at university.

We organised a conference in Bratislava and a workshop in Mala Lucivna about motivation and preparation of handicapped students for university study, integration and counselling services at school and university. Both meetings were a good opportunity for Slovak specialists who are involved in work with visually impaired people to exchange their experiences with foreign colleagues.

\subsection{Activities Aimed at Visually Impaired Students}

In the last academic year, two blind and three partailly sighted students studied at our university. They studied journalistics, law, pedagogics, history and mathematics.

They have received aid through preparation of study material, courses for electronic compensatory techniques and pedagogical - psychological counselling.

Before the blind students started to study at the University, they had gone through the mobility training and courses on special technical equipment (Eureka) by specialists from the Union of the Blind and Partially Sighted and courses 
on special computing in our Centre. They had already learned type-writing at high schools but they had not any experiences with computers. We trained them to use computer and special devices (Braille line and printer, voice output), the basic skills for using MS DOS and word processor (Word Perfect 5.1). Then we have been continuosly providing them with counselling about technical equipment of the Centre when it was needed. The counselling was provided also for partially sighted students, teachers from special schools for visually impaired students and for students of educational study (future teachers).

The essential condition is that visually impaired students should have studied scientific literature at their disposal in parallel with their fully-sighted peers. To accomplish that the Centre has been compiling and providing needed study materials (lecture notes, books, exercises) in the digital form, which was easily transformed into the Braille or large print, or displayed on the Braille line. This kind of work has been done by students from our faculty. I must appreciate that in current difficult economical situation, the main motivation for them was possibility to work with technique of high quality and learning of new technology. We are making use following technologies:

- 1. Transformation of the printed text into digital form using OCR system: scanner - computer - recognizing software (Recognita). Then we can print the text on Braille printer or it can be read through the Braille line or voice output. We can transform the digital information into form usable by Eureka using special software.

- 2. Text of the low quality, which is difficult to recognize by recognizing software, has been typed by students on computers.

- 3. Great amount of study material is recorded on audio-tapes. Unfortunately, our blind students prefer listening the tapes to using computers because of their undeveloped computer literacy. This fact implies two kinds of problems:

First, it is more difficult to find students of our faculty who are willing to record audio-tapes than students willing to use computers.

Second, it is more expensive to store data on audio-tapes than on flopydisks. In future we plan to use multimedia systems to transform analogue information to the digital form.

Great problem for us was to find students of similar study fields, who would have been preparing study materials of individual subjects. The reason of that was that not all handicapped students could live together with their schoolmates because of unsuitable accomodation conditions, so they lost contacts with them.

\subsection{External Activities and Cooperation}

Except of activities mentioned above we went on in trying to map the situation in. Slovakia for the future interest and plans of visually handicapped secondary school students in academic study. While making the survey of the situation in Slovakia, we have established contacts with teachers and pupils in special schools 
in many research institutions and faculties, whose competence and knowledge is related to our problems and thus we need their cooperation.

It would be naive to think that the Centre would work properly if we did not focus our activity also on wide circle of population. It seems it will be a longterm process of teaching not only the academic public to accept handicapped students, communicate with them, understand their needs and demands and form a proper psychological climate for their study and life.

There has been a trend in the education of the blind to concentrate (and somehow separate) them into special schools and institutions in our country and elsewhere in Europe. Such primary schools are located in the towns of Levoa and Bratislava.

All the achievements mentioned above wouldn't have been received without support of many institutions. On behalf of all I would like to appreciate the university's attitude towards the project. Especially the financial support in a present difficult economical situation was very helpful.

I must mention a cooperation with Slovak Blind and Partially Sighted Union too. The cooperation is very important for us. People from the union have helped us to understand better needs of blind and we have solved together a few technical problems concerning the adaptation of special devices for Slovak national environment.

The cooperation with the Western partners - German, English and Czech - has been very good. Clear rules, equivalent position of all partners and large indepedence in concrete decisions are main features of our cooperation.

\section{Conclusions and plans for the future}

The integrated education in Slovakia nearly does not exist. Conditions for study and living for visually impaired people allow them to choose only from one or two possible properly supported choices. The only solution of this situation is the establishment of a properly supported system of integrated education acting parallel with the special education, with increasing role and responsibility towards higher level of education. But there is a great lack and an urgent need of qualified staff and support services for the integrated education. Opening of the Centre at Comenius University in November 1993 was the first step to the really integrated education which needs to be followed by other concrete measures. Two years experience within the project opened new horizonts, needs and demands.

Because our TEMPUS project will finish this year, we have applied for the next one. If it is accepted we plan to go on through the following activities:

- 1. The establishment of the Distributed Network of Support Services for Visually disabled University Students (Expanding of the activities of the Support Centre at Comenius University as a coordinating body of the network including distance study, implementation of new communication and computer technology for remote provision of services, creation of the research and production unit for the tactile graphics). The network will consist of the 
main centre and three local centres at universities over the country. We have already opened first contacts with the universities in Bansk Bystrica, Koice and Nitra. Later, other local centres could be created according to the incidence and demands of visually disabled students.

In this activity will participate also our western partners:

- National Council for the Blind of Ireland will participate in the establishment of distributed network of support services for visually disabled university students including the distance study.

- The main role of the Royal National Institute for the Blind would be in the training and support infrastructure development.

- Loughborough University of Technology will guide the establishment of a research and production unit for tactile graphics by advising on appropriate technology.

- 2. Establishing new possibilities for preparation of professionals for integrated education and rehabilitation of visually disabled persons (postgraduate courses for educational counsellors and/or itinerant teachers, basic courses for mainstream teachers, courses for professional instructors of social rehabilitation).

This activity will make use of the outcomes of others activities - in the field of informatics, adaptive technology and tactile graphics.

The best place to realize this activity is at the Department of Typhlopedology at Faculty of Pedagogics because of its influence on future teachers and experts.

- 3. Development of new courses supporting integrated education for future mainstream teachers of sciences and informatics and development of intensive courses for pre-school training (both in primary and secondary education). Courses should be focused on technologies of developing educational computer microworlds with specially adapted graphics for partially sighted students as well as for non-handicapped students to understand problems of handicapped in modern integrated school. New educational activities should be "children centred" contrasted to more traditional "teacher centred" activities. Corresponding in-service training should be developed for teachers of elementary and secondary schools.

To succeed in this effort we decided to make extensive use of the newest implementation of Logo language, called Comenius Logo for Windows. Logo is a creative environment developed specially for children to support their logical mind and common sense abilities by making them solve simple problems - they are planning, decomposing problems into subproblems, and combining partial results into final solutions. The Logo environment has all promises to support "children centred" teaching/learning activities and has been successfully used in both mainstream education and special education for mentally disabled, for handicapped children etc. throughout the world. Its new implementation, Comenius Logo for Windows is extremely powerful implementation which stresses easy visualization of activities (by letting objects move all over the screen, by popular turtle graphics using multiple parallel turtles etc.). 
We plan to focus the courses around developing small projects (Logo microworlds) which will illustrate the way handicapped children have to make the communication, to learn, to entertain. We believe that graphical and multimedial features of Comenius Logo environment are suitable for developing, implementing, and evaluating such microworlds, and for learning the educational principles of such applications. Moreover, we plan to develop a course devoted to the ways the special technology for the handicapped is used. This course should make use of new developments of active learning environments, which may positively influence traditional special education.

At the beginning of May we applied also for COPERNICUS project together with partners from Scotland, Finland, Austria and Hungary. A title of the project is: "Remote Service Provision for People with Disabilities" and it seems to be a technology demonstrator project based on a multimedia training system for visually handicapped using internet, modem and ISDN links.

- 1. In this project we plan to extend our services to allow students throughout Slovakia to participate in the educational process via telecommunication's links, concentrating on text based services such as "talking books".

-2 . We would like to adapt the new technology, which is successfuly used in some western countries, for our national environment and develop needed software products for IBM PC and SUN Unix computing systems or for special electronical equipement and computers for the blind.

- 3. We have some experiences with hypertext systems and we plan to develop applications, which could enable visually impaired people to use and efectively manipulate multimedia information.

Many suggestions for these activities come from Slovak Blind and Partially Sighted Union which will also participate in all of them as a representant of interests of visually disabled people, they will use its long time experience in provision services to visually disabled people and they will transfer gained knowledge and experience to the general visually disabled community.

There is much more to run across - problems and successes. We must go on to achieve many interesting results, which I am sure will be of interest for both of you and us. Cross your fingers.

\section{References}

1. Mendelova, E.: The problems and prospect of building the Centre at Comenius University, New Study and Vocational Possibilities for Visually handicapped Students, Proceedings, The International Conference, January 31 - February 2, 1993, Bratislava

2. Waczulik, J.: Tempus JEP 2423: New study and vocational possibilities for visually handicapped students, Individual Institutional Report, Comenius University Bratislava, Academic year 1992/93 
3. Blaho, A., Kalas, I., Tomcsanyi, P.: Comenius Logo: Environment for teachers and Environment for learners, Proc. of the 4th European Logo Conference, Suppl. pp. 1-11, Athens 